\title{
Academic-related stress and prevalence of migraine and tension-type headaches amongst undergraduates of Delta State University, Abraka, Nigeria.
}

\author{
Omogbiya A.I. ${ }^{1}$, Anachuna K.K. ${ }^{2}$, Umukoro E.K. ${ }^{1}$, *Moke E.G. ${ }^{1}$, Nzei A. ${ }^{1}$
}

\begin{abstract}
Objective: This study aimed at determining the prevalence of migraine and tension-type headaches amongst undergraduates of Delta State University (DELSU), Abraka, Delta State, Nigeria and its relationship with academic related-stress.
\end{abstract}

Methods: A cross-sectional survey among 432 undergraduate students across the eleven Faculties of DELSU, Abraka, Nigeria, using questionnaires to determine the prevalence of migraine headache $(\mathrm{MH})$ and tension-type headache (TTH). The data extrapolated were analyzed with SPSS statistical software (version 20).

Results: MH was shown to have a high prevalence (198, 45.8\%) among student of DELSU. Photophobia accompanied most MH episodes more than phonophobia, nausea, vomiting. Similarly, TTH was also very prevalent $237(54.9 \%)$ amongst students of DELSU with females being more vulnerable than male. Spearman's correlation analysis revealed that the prevalence of MH and TTH is strongly associated to student's academic-related activities.

Conclusion: Academic-related stress activities were major predisposing triggers for the prevalence of both headaches.

Keywords: Abraka, academic-related stress activities, DELSU, migraine, stress, tension-type headache,

*Corresponding author

Moke, E.G.

ORCID-NO: http://orcid.org/0000-0002-4709-7474

E-mail: hiligoodies@gmail.com

${ }^{1}$ Department of Pharmacology and Therapeutics, Faculty of Basic Medical Sciences, College of Health Sciences, Delta State University, Abraka, Delta State, Nigeria

${ }^{2}$ Department of Physiology, Faculty of Basic Medical Sciences, College of Health Sciences, Delta State University, Abraka, Delta State, Nigeria 


\title{
Stress Lié à la Scolarité et Prévalence de la Migraine et des Céphalées de Tension Parmi les Étudiants de Premier Cycle de la Delta State University, Abraka, Nigéria.
}

\author{
Omogbiya A.I. ${ }^{1}$, Anachuna K.K. ${ }^{2}$, Umukoro E.K. ${ }^{\text {, }}$ *Moke E.G. ${ }^{1}$, Nzei A. ${ }^{1}$
}

\section{Résumé}

Objectif: Cette étude visait à déterminer la prévalence de la migraine et des céphalées de tension chez les étudiants de premier cycle de la Delta State University (DELSU), Abraka, Delta State, Nigeria et sa relation avec le stress scolaire.

Méthodes: Une enquête transversale auprès de 432 étudiants de premier cycle dans les onze facultés de DELSU, Abraka, Nigeria, à l'aide de questionnaires pour déterminer la prévalence des migraines $(\mathrm{MH})$ et des céphalées de tension (TTH). Les données extrapolées ont été analysées avec le logiciel statistique SPSS (version 20)

Résultats: MH s'est avéré avoir une prévalence élevée (198, 45,8\%) parmi les étudiants de DELSU. La photophobie accompagnait la plupart des épisodes de MH plus que la phonophobie, les nausées et les vomissements. De même, le TTH était également très répandu 237 (54,9\%) parmi les étudiants du DELSU, les filles étant plus vulnérables que les garçons. L'analyse de corrélation de Spearman a révélé que la prévalence de MH et de TTH est fortement associée aux activités académiques des étudiants.

Conclusion: Les activités de stress liées aux études étaient des déclencheurs prédisposants majeurs à la prévalence des deux maux de tête.

Mots-clés: Abraka, activités de stress académique, DELSU, migraine, stress, céphalées de tension

*Corresponding author

Moke, E.G.

ORCID-NO: http://orcid.org/0000-0002-4709-7474

E-mail: hiligoodies@gmail.com

${ }^{1}$ Department of Pharmacology and Therapeutics, Faculty of Basic Medical Sciences, College of Health Sciences, Delta State University, Abraka, Delta State, Nigeria

${ }^{2}$ Department of Physiology, Faculty of Basic Medical Sciences, College of Health Sciences, Delta State University, Abraka, Delta State, Nigeria 


\section{INTRODUCTION}

Headache is a common debilitating chronic vascular disorder of neurologic origin characterized by painful symptomatic manifestations primarily around the head or neck axis $(1,2)$. It contributes immensely to reduced functional efficiency and work output as well as impact the overall quality of life of its sufferers, thus constituting a burden to societal economic development (3-5). Headache disorders have been ranked among the top ten global disabling diseases (5); and according to the International Classification of Headache Disorders (ICHD), it can be primary or secondary (5). Primary headaches characteristically devoid of any underlying disease condition or structural problem accounts for about $47 \%$ of all known and reported headaches globally in terms of prevalence $(2,6)$. Most common among primary headaches are migraine headache $(\mathrm{MH})$ and tension-type headache (TTH) $(2,7)$; with worldwide statistical reports on the prevalence ratio for tension-type, migraine and chronic daily headaches revealed as: $38 \%$ : $10 \%: 3 \%$, respectively $(2,6)$. Furthermore, lifetime prevalence indicate that females are more vulnerable to headache attacks (of any kind) than male with their ratio reported as $99 \%$ (TTH - $88 \%$; MH - 25\%) : 93\% (TTH -69\%; MH -8\%) (2).

Headaches are categorically diagnosed as definitive (detail clinical examination by a headache specialist; represents the goldstandard) or probable (interviews by nonclinicians, self-reported questionnaire, or combining screening questionnaire and interview by a physician) (8). Probable headache diagnostic tools derived from the ICHD recommended criteria are especially employed in robust population-based studies though with less relative validity compared to definitive diagnosis (8-10). According to ICHD-III $\beta$, migraine headache $(\mathrm{MH})$ is generally typified by one-sided moderate to severe spiraling pain on the head $(3,9,11)$. Characteristically, $\mathrm{MH}$ begins dully but gradually develops into more throbbing or pulsating forms and are often accompanied by nausea, vomiting, photophobia (light-sensitive) and phonophobia (sound-sensitive) (12). On the other hand, tension-type headache (TTH) also known as stress headache reflects mild to moderate pain characterized by sustained tight band-like (squeezing) feelings (pressure) around the head (13). Evidence in documented literature have attributed stress as the greatest potential trigger/aggravator of most primary headaches $(12,14)$. Other lesser associated-risk factors include family-related history, BMI, smoking, sleeping problems, eating habits, menstruation (due to hormonal imbalance in women) and temperature (14-16).

Stress, although largely a defensive physiologic responsive component vital to human survival (17), is also widely thought of as a natural phenomenon occurring in abnormal situations wherein an individual lack the capable physiologic prerequisites to deal with a perceived danger or cope with a form of or set of activities $(18,19)$. According to the American Psychiatric Association (APA), stress generally manifest as either physical (e.g. intense physical labor, overexertion, dehydration, musculoskeletal misalignment/imbalances) or psychological (e.g. emotional -fears, resentment, bereavement; mental -information overload, pressure to excel, unrealistic deadliness) tensions (20). There are strong assertions that abnormally-sustained stress (physical or psychological) is highly common across all age groups including students and has been directly attributed as a greater predisposing factor (compared to irregular sleep, poor eating habits etc.) for chronic neurological problems including 'headache' (primary headache specifically) among tertiary university students $(5,10,21,22)$.

Studies that include physical stressful events in the context of academic-related stress activities and its impact on primary headaches among students of tertiary institution seem to be under-reported. The expression 'academicrelated stress activities' used in this study refers not only to mental tension (concentration during lectures, studying for tests and examination) but also to other physically exhaustive events (e.g. waking up early to attend lectures, long distant walks to lecture venues, long duration of overlapping lectures [as high as 12 hours long], overcrowded lecture halls, prolonged standing positions during lectures due to inadequate sits, constantly changing lectures venues, dehydrations, noise especially from running generating sets) experienced during days of academic activities. Based on available evidence (4), the risk of developing headache among tertiary institution students may even spike in low-income and developing nations (with limited educational resources and poor infrastructure) including Nigeria as reports indicates $(22,23)$ due to increased stressful demands. To the best our knowledge, no study has reported the prevalence of MH and TTH and the possible impact of academic-related stress among tertiary institution students in Delta State University and 
surrounding Southern States in Nigeria.

This study therefore sought to investigate the prevalence of probable migraine and tension-type associated headaches amongst undergraduates of Delta State University, Abraka, Delta State, South-South Nigeria. The study also evaluated in the same population the holistic relationship between the academicrelated stress activities and migraine and tensiontype headaches.

\section{MATERIALS AND METHODS}

The study design was a descriptive crosssectional survey carried out between April and June 2018 among undergraduate students of Delta State University, (DELSU) Abraka. DELSU currently has eleven faculties distributed across 3 different campuses within Delta State. The institution hosts an average of about 8,000 undergraduate students across the respective faculties per academic session. From this population size, an estimated sample size of 381 was obtained based on the Slovin's formula for sample size calculation (24). Only undergraduate students of Delta State University (DELSU), Abraka, were enrolled in the study between April to June, 2018. Based on faculty stratification, random distribution of 440 questionnaires among undergraduate students of the eleven faculties (40 per faculty) of DELSU was conducted of which 432 were successfully reclaimed and data used for the study. Every faculty returned the completed questionnaires assigned to them except for Faculties of Management Sciences and Basic Medical Sciences that returned 36 and 38 respectively. Ethical approval was gotten from the "Ethics Committee" of the Faculty of Basic Medical Sciences, DELSU, Abraka, and oral informed consent was obtained from the students before data collection.

The survey instrument for data collection was a well-structured 5-part questionnaire as previously described (10) with modifications. Part one contained general information on students' demographics (sex, age, marital status, department, level and faculty of study). Part two evaluated general headaches using a dual-phase rationale screening tool; phase I included questions like experiencing and frequency of headache attack. To minimize the occurrence of overlap of other probable headaches, only students who responded positively to academic related activities proceeded to phase II screening where the severity of the headache (mild, moderate, severe, very severe), time and period of occurrence were addressed. Parts three and four evaluated generally for $\mathrm{MH}$ and TTH. Part three employed the ID Migraine ${ }^{\mathrm{TM}}$ (Pfizer Inc., New York, NY, USA) assessment tool (10). It comprises of a set of questions that specifically determine probable $\mathrm{MH}$ according to the ICHDIII $\beta$ criteria. Students who responded $70 \%$ and above of the desirable answers were considered sufferers of migraine. Part four utilizes the ICHD-III $\beta$ criteria for evaluating probable TTH (9). Students who gave the desired answer were considered to sufferers of TTH. In the final $\left(5^{\text {th }}\right)$ part, we modified the method of Mukadder Mollaoglu's Assessment List of Trigger Factors $(19,25)$ to determine the degree of academicrelated stress activities common among the study population on the students' quality of life.

The SPSS statistical software (Version 20) and Microsoft excel package were used in analyzing data obtained herein. By way of descriptive statistics, results were presented in tables and charts wherein categorical variables were described as frequency and percentage. Also, Spearman correlation method for analyzing statistical data was used as comparative test tool for the relationship between stress and migraine or between stress and tension-type headache. The differences between groups were considered significant when $\mathrm{P}$ was less than $0.05(\mathrm{p}<0.05)$.

\section{RESULTS}

The demographic characteristics of the respondents according to age, sex and marital status revealed that majority of the students were within the age range of 21-25 years (Table1). A number of the students reported that they had experienced headache in the last 3 months of which $53.7 \%$ stated that the pain from their headache was moderate, and only a few (3.2\%) reported that theirs was very severe. About twothird of the respondents $(63.0 \%)$ also claimed to have suffered from headache attacks during the afternoon than any other time while $46.1 \%$ reported mid-semester as their most vulnerable semester period (Table 2).

According to the study respondents, a total of $198(45.8 \%)$ students said they experienced hemicranial headaches located on one side of the head (indicative of probable migraine) as compared to $234(54.2 \%)$ who had generalized headaches. Gender differences showed that $\mathrm{MH}$ is more prevalent in female $(25.7 \%)$ than in male $(20.1 \%)$. Moreover, the total percentage of respondents that reported nausea, vomiting, phonophobia (soundsensitivity) and photophobia (light-sensitivity) as 
headache accompanying symptoms were $57.0 \%$, $32.5 \%, 70.9 \%$ and $72.7 \%$ respectively (Table 3 ). The prevalence of TTH (tension-type headache) is depicted in Table 4. The mean value of respondents who suffered headaches on both sides of the head $(220,51.0 \%)$ and experience a tight band-like feeling around their heads $(253$, $58.6 \%)$ was $237(54.9 \%)$ suggesting probable TTH. Females also reported a higher prevalence $(32.2 \%)$ of TTH than male $(22.7 \%)$. The total percentage respondents who reported stress as trigger factor of the headache (of any severity) they experienced were higher $(85.3 \%)$ than those that reported sleep deprivation (68.1\%), irregular meals $(59.5 \%)$ and alcohol intake $(26.2 \%)$. The graphical illustrations shown in Figures 1 and 2 on the prevalence of primary headache among students of the DELSU across the eleven Faculties revealed that students in the Faculties of Science, Law, Arts and Management Sciences are more predisposed to MH than the other faculties, whereas; those in Faculties of Pharmacy, Agriculture and Basic Medical Sciences suffer more from TTH.

Anxiety toward academic-related activities was employed as a tool to predict the presence of stress following systematic computation of score that evaluated academicrelated activities. As shown in Table 5, 42.4\% of respondents had increased anxiety during days of intense academic activities (DIAA) compared to the $(13.7 \%)$ on DMAA and (7.6\%) on DNAA. In total, $63.7 \%$ of claimed that they are especially anxious or stressed during days academic-related activities compared to $36.3 \%$ who claimed they never felt any anxiety (Table 5).

The results of correlated impact of academic-related stress activities on migraine or tension-type headaches among students of Delta State University is presented in Table 6. As shown by Spearman's rank correlation analysis, there was significant $(p<0.05)$ relationship between academic-related stress level experienced (SLE) and migraine (headache on one side of head, OSH), as well as between academic-related SLE and tension-type headache (headache on both sides of head, BSH).

\section{DISCUSSION}

Global consensus affirms headache, which a chronic brain-originating neurovascular disorder as are current painful and debilitating condition affecting generally people of all ages indiscriminately $(1,22)$. This consensus on headache (especially the primary forms) has been reported to be alarmingly very common among undergraduate students of tertiary institutions globally (22). A study conducted among undergraduate students of three tertiary institutions in Kwara State, in North-Central Nigeria, positively confirmed the prevalence of primary headache (mainly migraine and tensiontype) as a common unpleasant condition (4). The findings from our broad-based cross-sectional study revealed the prevalence of primary headaches (MH and TTH) among undergraduate students and a significant correlation between academic-related stress activities and primary headaches.

Specifically, the study revealed that $\mathrm{MH}$ is prevalent amongst undergraduate students of DELSU. Of the 432 active participants, 198 (45.8\%) reported to have migraine according to the ID-Migraine ${ }^{\mathrm{TM}}$ evaluation tool. The reliable validity of the ID-Migraine ${ }^{\mathrm{TM}}$ tool in diagnosing probable migraine base on the ICHD-III $\beta$ criteria have been previously reported with $95 \%$ CI sensitivity / specificity $(10,21)$. Alarmingly, this figure surpasses global statistical estimate of $11 \%$ has been reported (2). Also, the prevalence of $\mathrm{MH}$ was found to be significantly higher in females than in males, thus supporting previous findings (2). This could be attributed partly to the frequent hormonal imbalances (e.g. higher estrogen levels) that females especially in their prime experience. Besides, the increase in number of female respondents enrolled in the study as compared to male may have also contributed to this increased prevalence in female. Most student migraineurs in this study were between the age bracket of 20-25, were singles and in either 100 Levels or their final year. This is quite noteworthy, since pressure to settle down and compete for the demands for excellence immediately after gaining admission or to satisfy the institution graduating requirements is especially very high in these two spectrums of class level of study. Moreover, most migraineurs rated their headache as moderate intensity (53.7\%); only a few (3.2\%) said theirs was very severe. Across the various faculties, Science and Law reported the highest prevalence. Comparative-wise using Faculty of Medical Sciences as a reference point, migraine prevalence of undergraduate medical students $(16,42.1 \%)$ reported in our study was notably higher than that reported for undergraduate medical students of University of Gonder in North-Western Ethiopia (13.1\%) (5) and National Hospital, Nairobi, Kenya (33.8\%) (26) in Africa as well as Soochow University (7.9\%) (10) in China. Similarly, In Nigeria, our study 
also carries a higher prevalence of $\mathrm{MH}$ compared to that reported previously in Kwara, Ilorin for three tertiary institutions, which showed a combined prevalence of $3.9 \%$ (4). According to meta-analytical investigations, the variations in these reports may in part be related to factors such as geographical diversification, population and race (2).

Our result further reported an alarming prevalence of probable tension-type headache (TTH) amongst the study population. According to the ICHD-III $\beta$ criteria for TTH (8-10), average summation (using headache on both sides of the head and tight-band feelings) indicate that 54.9\% of students' respondents are sufferers of TTH with female $(139 ; 32.2 \%)$ being more vulnerable than male $(98 ; 22.7 \%)$. Students of the faculties of Pharmacy $(27 ; 67.5 \%)$, Agriculture (25; $62.5 \%$ ) and Basic Medical Sciences (24; 60.0\%), respectively, reported the highest prevalence for TTH. Overall, our study showed that undergraduate students of DELSU are more susceptible to TTH than MH. The prevalence of TTH (54.8\%) in our study bear similarity to the respective findings of (14) and (27), although higher than that reported for students of Isfahan University, Iran (44.6\%) (23). Additionally, we observed in this study that stress $(85.4 \%)$ was the main trigger for the prevalent episodes of TTH among student respondents followed by sleep deprivation (68.1\%) irregular meal (60.6\%) and alcohol, thus corroborating previous findings $(5,10,21)$.

Based on the modified Mukadder Mollaoglu's Assessment Trigger tool $(10,25)$, qualitative assessment of the association between academic-related stress activities and probable primary headache prevalence in the study population, revealed that majority of the students (42.4\%) felt increasing and helplessly anxious (stress predictor) during days of intense academic activities (DIAA) compared to DMAA (13.7\%), DNAA (7.6\%) and NEVER (33.6\%). Most even claim to have skipped lectures and sometimes tests due to increased anhedonia (loss of interest in food or other pleasure-seeking activities) toward their academic and social routine. In addition to mental stress, the increased anxiety found among the study population could in part be attributed to sustained physical factors like musculoskeletal strain due to prolonged sitting / standing during lectures, over-crowded/noisy (generators) lecture rooms, fatigue, dehydration, long duration of lectures etc. This agrees strongly with posits from previous studies which suggests that physical and environmental stressors along with life-style negatively impact the quality of life of university students $(22,27,28)$.

Spearman's Rank correlation coefficient analysis showed that academic-related stress activities had significant association on the prevalence of probable migraine $(\mathrm{MH})$ or tension-type headache (TTH) among DELSU undergraduate students. The tail end of the correlation coefficient in this study showed an associative significance $(\mathrm{p}<0.016)$ for $\mathrm{MH}$ and $(\mathrm{p}<0.017)$ for TTH, respectively, in relation to academic-related stress activities; thus, supporting findings from previous reports $(29,30)$. Some studies have however reported negative significant correlation between academic-related stress and primary headache have been documented (22). These discrepancies on the associative correlation between academicrelated stress and prevalence of primary headache (MH and TTH) among students of tertiary institutions in the present study and those of other institutions previously reported could in part be attributed to differences in study population, methodology, educational system/curriculum and technological availability as well as period of the semester in which the study was conducted.

Notwithstanding, the present study is not devoid of limitations. Amongst such are: lack of specified expert diagnosis by qualified neurologist. This likely increases the chances of wrong diagnosis of either $\mathrm{MH}$ or TTH within the study population. Another limitation was the narrowed primary headache variables (MH and TTH) assessed herein. Chronic headache, cluster headache and non-specific headache which are less forms of primary headaches were not evaluated alongside MH and TTH in the study population. Also, since assessment was based on self-reporting and memory retrieval of past experiences of respondents in our study, subjective reasonings may have influenced some responses leading to bias.

\section{CONCLUSION}

Probable Migraine (MH) and tensiontype headache (TTH), are the two most prevalent sub-types of primary headache affecting general population including students of tertiary institutions. This study provides valuable preliminary data on the prevalence of migraine and tension-type headaches and possible association of academic-related stress as attributable factors among students of Delta State University (DELSU), Abraka, South-South Nigeria. Compared to undergraduate students of 
other institutions as previous reports indicated, DELSU undergraduate students recorded higher prevalence of $\mathrm{MH}$ and $\mathrm{TTH}$, with female being more sufferers than their male. This study has also shown for the first time that significant positive association exist between academicrelated stress activities and prevalence of $\mathrm{MH}$ as well as TTH among DELSU undergraduate students, thus constituting potential predisposing triggers for headaches disorders. Although more confirmatory studies that include headache expert evaluation and diagnosis are needed to support the findings from the present study, better academic-friendly conditions (e.g. standard lecture/tests/examination time-table schedule, short lecture sessions, appropriate class population, well-ventilated, and noise-free classroom with sitting capacity) that encourages less stress and fatigue while improving functional efficiency and hedonic (food- or pleasureseeking and sociability) habits are strongly recommended.

\section{Conflicts of interest: None.}

Acknowledgements: Authors wish to express their profound gratitude to Miss Ottah, Jasmine Ogechukwu for tirelessly assisting in the distribution process of the survey questionnaires across the different Faculties. Special thanks go also to all the respondents who voluntarily consented to the study process.

\section{REFERENCES}

1. Onwuekwe I, Onyeka T, Aguwa E, EzealaAdikaibe B, Ekenze O, Onuora E. Headache prevalence and its characterization amongst hospital workers in Enugu, South East Nigeria. Head Face Med. 2014; 10: 48.

2. Oshinaike O, Ojo O, Okubadejo N, Ojelabi O, Dada A. Primary Headache Disorders at a Tertiary Health Facility in Lagos, Nigeria: Prevalence and Consultation Patterns. BioMed Research International. 2014; Article ID 782915 , 5 pages.

3. Ikenna OO, Ezeala-Adikaibe B, Oluchi SE. Neurological disease burden in two semi-urban communities in South East Nigeria. Nig J Med. 2012;21(3):317-319.

4. Sanya EO, Desalu OO, Aderibigbe SA, Kolo PM, Mustapha AF, Adeyanju OA. Prevalence and clinical characteristics of headaches among undergraduate students in three tertiary institutions in Ilorin, Nigeria. Niger J Clin Pract. 2017; 20(11): 1411-1416.

5. Birru EM, Abay Z, Abdelwuhab M, Basazn A, Sirak B, Teni FS. Management of headache and associated factors among undergraduate medicine and health science students of University of Gondar, North West Ethiopia. The Journal of Headache and Pain. 2016; 17:56

6. Stovner LJ, Hagen K, Jensen R, Katsarava Z, Lipton R, Scher A, et al. The global burden of headache: a documentation of headache prevalence and disability worldwide. Cephalalgia. 2007;27(3): 193-210.

7. Clinch CR. Evaluation \& Management of Headache. In: South-Paul JE, Matheny SC, Lewis EL, editors. CURRENT Diagnosis \& Treatment in Family Medicine. 3rd ed. New York: Lange Medical Books/McGraw-Hill, 2011; p. 301-306.

8. Hagen $\mathrm{K}$, Åsberg AN, Uhlig BL, Tronvik E, Brenner E, Stjern M, et al. The epidemiology of headache disorders: a face-to-face interview of participants in HUNT4. The Journal of Headache and Pain. 2018; 19:25

9. International Headache Society (IHS). Headache Classification Committee of the International Headache Society (IHS): The International Classification of Headache Disorders, 3rd edition (beta version). Cephalalgia 2013;33(9): 629-808

10. Gu X, Xie Y. Migraine attacks among medical students in Soochow University, Southeast China: a cross-sectional study. J Pain Res. 2018; 11:771-781.

11. Weatherall MW. The diagnosis and treatment of chronic migraine. Ther Adv Chronic Dis. 2015; 6(3): 115-23

12. Simon RP, Greenberg DA, Aminoff MJ. Clinical neurology. 7th ed. New York: Lange Medical Books/McGraw-Hill, 2009.

13. Chowdhury D. Tension type headache. Ann Indian Acad Neurol. 2012; 15(Suppl 1): S83-8.

14. Almesned IS, Alqahtani NG, Alarifi JA, Alsaawy TN, Agha S, Alhumaid MA. Prevalence of primary headache among medical students at King Saud Bin Abdulaziz University for Health Sciences, Riyadh, Saudi Arabia. J Family Med Prim Care. 2018; 7(6): 1193-1196.

15. Straube A, Pfaffenrath V, Ladwig K, Meisinger C, Hoffmann W, Fendrich K, et al. Prevalence of chronic migraine and medication overuse headache in Germany - The German DMKG Headache Study. Cephalalgia 2010;30:207-213.

16. Iliopoulos $P$, Damigos D, Kerezoudi E, Limpitaki G, Xifaras M, Skiada D, et al. Trigger factors in primary headaches subtypes: a cross-sectional study from a tertiary centre in Greece. BMC Res Notes. 2015; 8: 393.

17. Chovatiya R, Medzhitov R. Stress, inflammation, and defense of homeostasis. Mol Cell. 2014; 54(2): 281-8.

18. Anbazhagan A, Soundar-Rajan LJ. A conceptual framework of occupational stress and coping strategies. ZENITH International Journal of Business Economics \& Management Research. 2013;3(5): 154-172.

19. Sandi C. Stress and cognition. Wiley Interdisciplinary Reviews: Cognitive Science. 
2013; 4: 245-261

20. American Psychiatric Association (APA) Diagnostic and statistical manual of mental disorders. 5th ed. Washington: American Psychological Association, 2014.

21. Al-Hashel JY, Ahmed SF, Alroughani R, Goadsby PJ. Migraine among medical students in Kuwait University. J Headache Pain. 2014;15: 26.

22. Zarea K, Rahmanib M, Hassanic F, Hakim A. Epidemiology and associated factors of migraine headache among Iranian medical students: A descriptive-analytical study. Clinical Epidemiology and Global Health. 2018; 6(3): 109-114

23. Ghorbani A, Abtahi SM, Fereidan-Esfahani M, Abtahi SH, Shemshaki H, Akbari M, et al. Prevalence and clinical characteristics of headache among medical students, Isfahan, Iran. J Res Med Sci. 2013; 18(Suppl 1): S24-27.

24. Galero-Tejero, E. (2011). A Simplified Approach to Thesis and Dis sertation Writing. Mandaluyong City: National Book Store, 2011; p. 43-44.

25. Mollaoğlu M. Trigger factors in migraine patients. J Health Psychol. 2013; 18(7): 984-994
26. Amayo EO, Jowi JO, Njeru EK. Headache associated disability in medical students at the Kenyatta National Hospital, Nairobi. East Afr Med J. 2002; 79: 519-23

27. Tandon R, Bhoi SK, Kalita J, Misra UK. Frequency and pattern of headache in medical residents and non-medical students in a tertiary care teaching hospital in North India. Journal of Evidence Based Medicine and Healthcare. 2018; 5(8): 631-638

28. Lebedeva ER, Kobzeva NR, Gilev DV, Kislyak NV, Olesen J. Psychosocial factors associated with migraine and tension-type headache in medical students. Cephalalgia.2017; 37(13): 1264-1271.

29. Shahrakai MR, Mirshekari H, GhanbariAT, Shahraki AR, Shahraki E. Prevalence of migraine among medical students in Zahedan Faculty of Medicine (Southeast of Iran). BCN. 2011; 2(2): 20-25.

30. Khan A, Khattak H, Jamali R, Rashid H, Riaz A, Ibrahimzai AK. Prevalence of migraine, its common triggering factors and coping strategies in medical students of Peshawar. Khyber Med Univ J. 2012; 4(4): 187-192. 
Table 1: Demographic characteristics of respondents

\begin{tabular}{llll}
\hline Variable & $\begin{array}{l}\text { Frequency } \\
(\mathbf{n = 4 3 2 )}\end{array}$ & $\begin{array}{l}\text { Percentage } \\
\mathbf{( \% )}\end{array}$ & $\begin{array}{l}\text { Cumulative } \\
\text { Percentage (\%) }\end{array}$ \\
\hline Age & & & \\
$15-20$ & 134 & 31.0 & 31.0 \\
$21-25$ & 227 & 52.5 & 83.6 \\
$26-30$ & 7 & 1.6 & 85.2 \\
$31-35$ & 63 & 14.6 & 99.8 \\
$36-40$ & 1 & 0.2 & 100.0 \\
Gender & & & \\
Male & 167 & 38.7 & 38.7 \\
Female & 265 & 61.3 & 100.0 \\
Marital Status & & & \\
Single & 423 & 97.9 & 97.9 \\
Married & 9 & 2.1 & 100.0 \\
\hline
\end{tabular}

Table 2: Prevalence of headache among undergraduates of Delta State University, Abraka

\begin{tabular}{lll}
\hline Determinants & $\begin{array}{l}\text { Frequency } \\
\text { (n=432) }\end{array}$ & Percentage (\%) \\
\hline Severity of headache in the last three months & 107 & 24.8 \\
Mild & 232 & 53.7 \\
Moderate & 79 & 18.3 \\
Severe & 14 & 3.2 \\
Very Severe & & \\
& & \\
Time of day headache was felt & 29 & 6.7 \\
Morning & 272 & 63.0 \\
Afternoon & 109 & 25.2 \\
Evening & 22 & 5.1 \\
Night & & \\
& & \\
Period of the semester headache was felt & 50 & 11.6 \\
Beginning (Majorly lectures) & 199 & 46.1 \\
Middle (Lectures and Tests) & 183 & 42.4 \\
End (examination period) & & \\
\hline
\end{tabular}


Table 3: Determinant of migraine prevalence among undergraduates of Delta State University, Abraka using the symptomatic characteristics of migraineurs based on ID- Migraine ${ }^{\mathrm{TM}}$ evaluation tool

\begin{tabular}{|c|c|c|}
\hline $\begin{array}{l}\text { ID-Migraine rating for symptomatic migraineurs } \\
\text { (more than } 2 \text { occurrences within the past } 3 \text { months) }\end{array}$ & $\begin{array}{l}\text { Frequenc } \\
y \\
n=432\end{array}$ & $\begin{array}{l}\text { Percentage } \\
(\%)\end{array}$ \\
\hline \multicolumn{3}{|l|}{ Headache felt on one side of the head } \\
\hline Yes & 198 & 45.8 \\
\hline No & 234 & 54.2 \\
\hline \multicolumn{3}{|l|}{ Gender differences for 'YES' respondents) } \\
\hline Male & 87 & 20.1 \\
\hline Female & 111 & 25.7 \\
\hline \multicolumn{3}{|l|}{ Accompanying symptoms: } \\
\hline \multicolumn{3}{|l|}{ Severity of headache accompanied by nausea } \\
\hline No headache & 192 & 44.4 \\
\hline Some headache & 161 & 37.3 \\
\hline Most headache & 55 & 12.7 \\
\hline All headache & 24 & 7.0 \\
\hline \multicolumn{3}{|l|}{ Severity of headache accompanied by vomiting } \\
\hline No headache & 292 & 67.5 \\
\hline Some headache & 95 & 22.0 \\
\hline Most headache & 36 & 8.4 \\
\hline All headache & 9 & 2.1 \\
\hline Severity of headache accompanied by & & \\
\hline $\begin{array}{l}\text { No headache } \\
\text { No }\end{array}$ & $\begin{array}{l}120 \\
181\end{array}$ & $\begin{array}{l}29.1 \\
41.9\end{array}$ \\
\hline Some headache & 82 & 19.0 \\
\hline Most headache & 43 & 10.0 \\
\hline \multicolumn{3}{|l|}{ All headache } \\
\hline Severity of headache accompanied by photophobia & 118 & 27.3 \\
\hline No headache & 224 & 51.9 \\
\hline Some headache & 67 & 15.5 \\
\hline Most headache & 23 & 5.3 \\
\hline All headache & & \\
\hline
\end{tabular}


Table 4: Determinant of tension-type headache (TTH) among undergraduates of Delta State University, Abraka using the ICHD-III $\beta$ rating characteristics of episodic tension-type headache

\begin{tabular}{|c|c|c|}
\hline $\begin{array}{l}\text { TTH rating by experiential characteristics (within } \\
\text { the past three months) }\end{array}$ & $\begin{array}{l}\text { Frequenc } \\
y(n=432)\end{array}$ & $\begin{array}{l}\text { Percentage } \\
(\%)\end{array}$ \\
\hline \multicolumn{3}{|l|}{ 1. Headache felt on both sides of the head } \\
\hline Yes & 220 & 51.0 \\
\hline No & 212 & 49.1 \\
\hline \multicolumn{3}{|l|}{ 2. Headache felt as tight bands around the head } \\
\hline Yes & 253 & 58.6 \\
\hline No & 179 & 41.4 \\
\hline \multicolumn{3}{|l|}{ Gender differences 'YES' respondents (mean of 1} \\
\hline \&2) & 98 & 22.7 \\
\hline Male & 139 & 32.2 \\
\hline \multicolumn{3}{|l|}{ Female } \\
\hline \multicolumn{3}{|l|}{ Trigger factors for TTH: } \\
\hline Severity of headache due to stress level experienced & 63 & 14.6 \\
\hline No headache & 182 & 42.1 \\
\hline Some headache & 138 & 31.9 \\
\hline Most headache & 49 & 11.3 \\
\hline \multicolumn{3}{|l|}{ All headache } \\
\hline Severity of headache due to irregular meal & 175 & 40.5 \\
\hline No headache & 167 & 38.7 \\
\hline Some headache & 62 & 14.4 \\
\hline Most headache & 28 & 6.4 \\
\hline \multicolumn{3}{|l|}{ All headache } \\
\hline Severity of headache due to sleep deprivation & 138 & 31.9 \\
\hline No headache & 148 & 34.3 \\
\hline Some headache & 114 & 26.4 \\
\hline Most headache & 32 & 7.4 \\
\hline \multicolumn{3}{|l|}{ All headache } \\
\hline Severity of headache due to alcohol intake & 319 & 73.8 \\
\hline No headache & 58 & 13.4 \\
\hline Some headache & 40 & 9.3 \\
\hline Most headache & 15 & 3.5 \\
\hline All headache & & \\
\hline
\end{tabular}




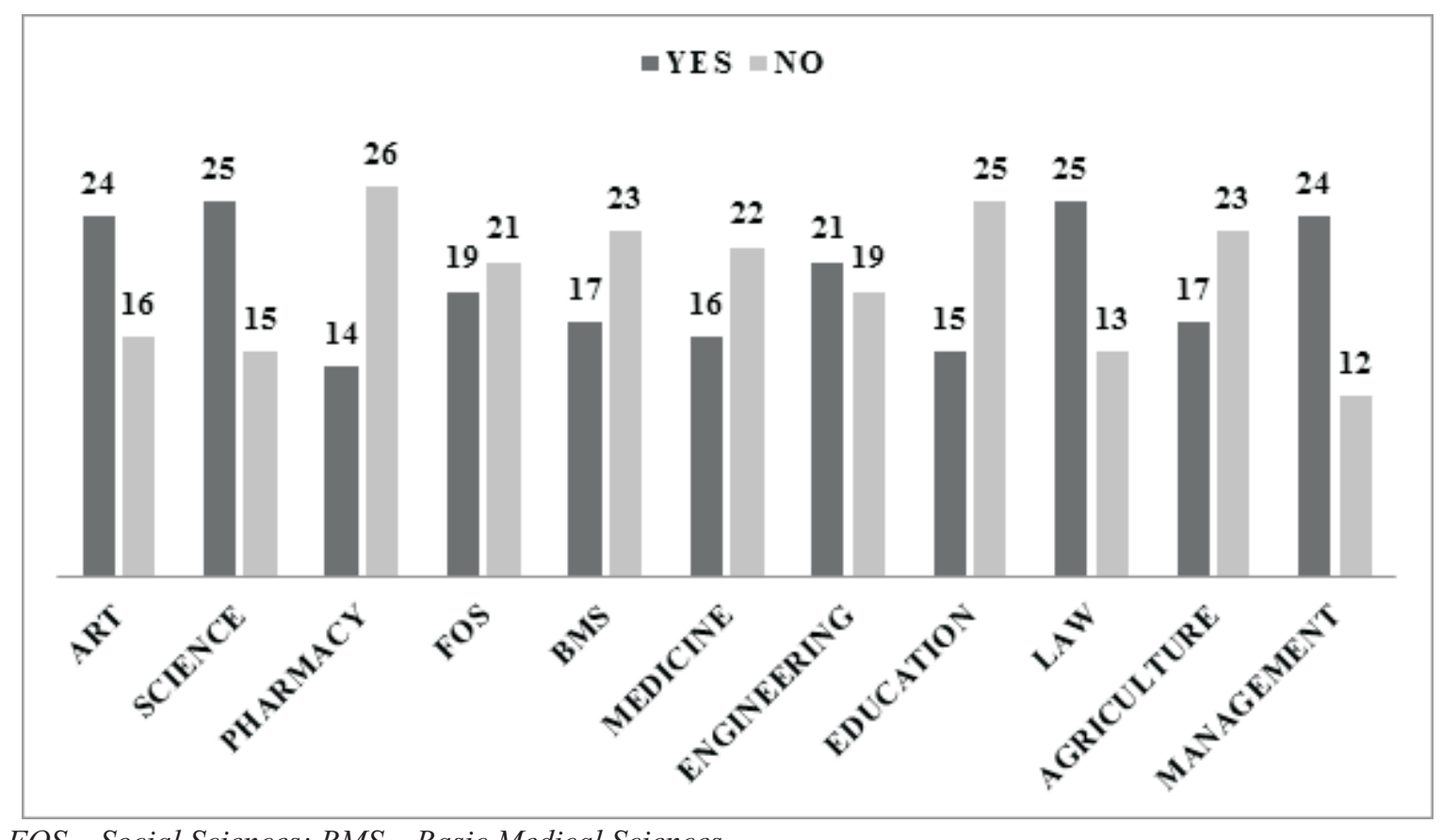

FOS - Social Sciences; BMS - Basic Medical Sciences

Figure 1: Prevalence of migraine headache among undergraduates of the different Faculties of Delta State University, Abraka. $(n=40)$ except for Medicine $(n=38)$; Law $(n=38)$; Management $(n=36)$.

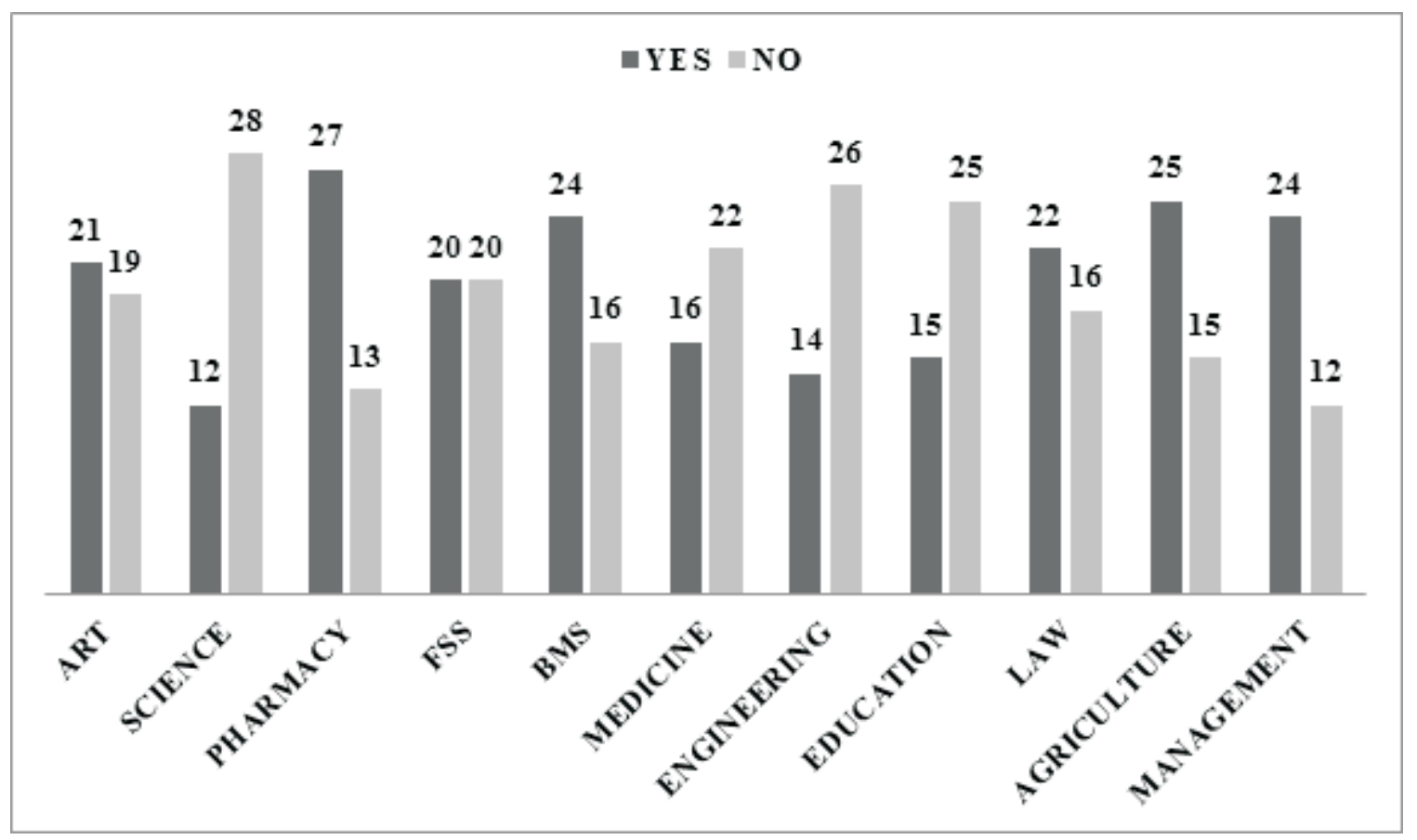

FSS - Social Sciences; BMS - Basic Medical Sciences

Figure 2: Prevalence of tension-type headache among undergraduates of the different Faculties of Delta State University, Abraka. $(n=40)$ except for Medicine $(n=38)$; Law $(n=38)$; Management $(n=36)$. 
Table 5: Academic-related anxiety among undergraduates of Delta State University, Abraka

\begin{tabular}{|c|c|c|c|}
\hline $\begin{array}{l}\text { Anxiety } \\
\text { ratings }\end{array}$ & $\begin{array}{l}\text { (stress) Frequency } \\
\text { (n) }\end{array}$ & Percent (\%) & $\begin{array}{l}\text { Cumulative Percent } \\
(\%)\end{array}$ \\
\hline NA & 157 & 36.3 & 36.3 \\
\hline DIAA & 183 & 42.4 & 78.7 \\
\hline DMAA & 59 & 13.7 & 92.4 \\
\hline DNAA & 33 & 7.6 & 100.0 \\
\hline Total & 432 & 100.0 & \\
\hline
\end{tabular}

Table 6. Correlations between academic-related stress and primary headaches

\begin{tabular}{|c|c|c|c|c|}
\hline \multicolumn{3}{|c|}{ Correlations of migraine headache } & \multirow{2}{*}{$\begin{array}{l}\text { OSH } \\
1.000\end{array}$} & SLE \\
\hline \multirow{5}{*}{ Spearman's rho } & \multirow[t]{2}{*}{$\mathrm{OSH}$} & $\begin{array}{l}\text { Correlation Coefficient } \\
\text { Sig. (2-tailed) }\end{array}$ & & $\begin{array}{r}-.119 * \\
0.016\end{array}$ \\
\hline & & $\mathrm{N}$ & 432 & 432 \\
\hline & \multirow{3}{*}{ SLE } & Correlation Coefficient & $-.119 *$ & 1.000 \\
\hline & & Sig. (2-tailed) & 0.016 & \\
\hline & & $\mathrm{N}$ & 432 & 432 \\
\hline \multicolumn{3}{|c|}{ Correlations of tension-type headache } & BSH & SLE \\
\hline \multirow{5}{*}{ Spearman's rho } & \multirow[t]{3}{*}{$\mathrm{BSH}$} & $\begin{array}{l}\text { Correlation Coefficient } \\
\text { Sig. (2-tailed) }\end{array}$ & 1.000 & $\begin{array}{l}-.114^{*} \\
0.017\end{array}$ \\
\hline & & $\mathrm{N}$ & 432 & 432 \\
\hline & & Correlation Coefficient & $-.114^{*}$ & 1.000 \\
\hline & \multirow[t]{2}{*}{ SLE } & Sig. (2-tailed) & 0.017 & \\
\hline & & $\mathrm{N}$ & 432 & 432 \\
\hline
\end{tabular}

*Correlation is significant at $P$ value $<0.05$ level (2-tailed). 